\title{
Vasopressin V2 is a promiscuous G protein-coupled receptor that is biased by its peptide ligands.
}

Franziska M. Heydenreich ${ }^{1,2,3 *}$, Bianca Plouffe ${ }^{2,4}$, Aurélien Rizk ${ }^{1}$, Dalibor Milićí, ${ }^{1,5}$, Joris Zhou ${ }^{2}$, Billy Breton $^{2}$, Christian Le Gouill ${ }^{2}$, Asuka Inoue ${ }^{6}$, Michel Bouvier $^{2, *}$ and Dmitry B. Veprintsev ${ }^{1,7,8, *}$

${ }^{1}$ Laboratory of Biomolecular Research, Paul Scherrer Institute, 5232 Villigen PSI, Switzerland and Department of Biology, ETH Zürich, 8093 Zürich, Switzerland

${ }^{2}$ Department of Biochemistry and Molecular medicine, Institute for Research in Immunology and Cancer, Université de Montréal, Montréal, Québec, Canada

${ }^{3}$ Department of Molecular and Cellular Physiology, Stanford University School of Medicine, Stanford, CA 94305, USA

${ }^{4}$ The Wellcome-Wolfson Institute for Experimental Medicine, School of Medicine, Dentistry and Biomedical Sciences, Queen's University Belfast, 97 Lisburn Road, Belfast, BT9 7BL, United Kingdom

${ }^{5}$ Department of Structural and Computational Biology, Max Perutz Labs, University of Vienna, Campus-Vienna-Biocenter 5, 1030 Vienna, Austria

${ }^{6}$ Graduate School of Pharmaceutical Sciences, Tohoku University, Sendai, Miyagi 980-8578, Japan.

${ }^{7}$ Centre of Membrane Proteins and Receptors (COMPARE), University of Birmingham and University of Nottingham, Midlands, UK.

${ }^{8}$ Division of Physiology, Pharmacology \& Neuroscience, School of Life Sciences, University of Nottingham, Nottingham, NG7 2UH, UK.

*Correspondence should be addressed to: fheyden@stanford.edu, michel.bouvier@umontreal.ca, dmitry.veprintsev@nottingham.ac.uk. 


\begin{abstract}
Activation of the $\mathrm{G}$ protein-coupled receptors by agonists may result in the activation of one or more $\mathrm{G}$ proteins, and in the recruitment of arrestins. The balance of activation of different pathways can be influenced by the ligand. Using BRET-based biosensors, we showed that the vasopressin V2 receptor activates or at least engages many different $\mathrm{G}$ proteins across all $\mathrm{G}$ protein subfamilies in response to its native agonist arginine vasopressin (AVP). This includes members of the Gi/o and G12/13 families that have not been previously reported. These signalling pathways are also activated by the synthetic peptide desmopressin and natural homologs of AVP, namely oxytocin and the non-mammalian hormone vasotocin. They demonstrated varying degrees of functional selectivity relative to AVP, as quantified using the operational model for quantifying ligand bias. Additionally, we modelled G protein activation as a Michaelis-Menten reaction. This approach provided a complementary way to quantify signalling bias, with an added benefit of clear separation of the effects of ligand affinity from the intrinsic activity of the receptor. These results showed that V2 receptor is not only promiscuous in its ability to engage several $\mathrm{G}$ proteins, but also that its signalling profile could be easily biased by small structural changes in the ligand.
\end{abstract}




\section{Introduction}

G protein-coupled receptors (GPCRs) are a family of membrane proteins involved in many physiological processes including vision, smell, hormone regulation and neurotransmission. Their extracellular ligand-binding sites and their impact on cellular signalling make them prime drug targets [1]. GPCRs translate ligand-binding events into cellular signals via activation of heterotrimeric $G$ proteins and arrestins. Despite a large variety of incoming signals, there are only 16 different G $\alpha, 5 \mathrm{G} \beta$ and $12 \mathrm{G} \gamma$ subunits $[2,3]$, two $\beta$-arrestins and two visual arrestins mediating intracellular signalling. Experimental evidence shows that many receptors are capable of activating or engaging more than one G protein isoform, not only within but also across the Gs/olf, Gi/o, Gq/11 and G12/13 subfamilies of heterotrimeric $\mathrm{G}$ proteins [4-11]. The realisation that some ligands can be agonists for one pathway and antagonists for another led to the development of the concept of biased signalling [12-17]. Importantly, such biased ligands are very promising pharmaceuticals because pharmacological benefits are often associated with one particular pathway while the undesired side-effects are mediated by another [13, 18-22]. To compare ligands with each other, a quantitative measure of their signalling efficacy towards individual effectors and their signalling bias is required.

Several approaches to quantify signalling bias have been suggested (reviewed in [21, 23]) the most widely used approach is based on the Black-Leff operational model [24-26]. This formalism describes the ligand binding and effector output of the receptors and provided a framework for the development of quantitative pharmacology [24]. One of the important aspects of this model is its simplicity while keeping the ability to capture important aspects of the signalling process. On the other hand, it is a heuristic model that links the signalling input (ligand binding) to the signalling output (response), without considering the underlying mechanisms. Alternatively, the process of the $G$ protein activation can be presented as an enzymatic reaction, in which the receptor is an enzyme which catalyses the nucleotide exchange in the $\mathrm{G}$ protein. This model is very insightful but as it considers $\mathrm{G}$ protein recruitment and nucleotide exchange, it is rather complex and contains multiple parameters. As our understanding of the molecular mechanisms involved in the receptor signalling and desensitisation improved, even more detailed descriptions of the signalling processes using quantitative systems pharmacology approaches have been developed [27]. These approaches hold a lot of promise, but the complexity of the signalling and the corresponding models requires a significant amount of diverse data to be collected, limiting its application for routine screening of compounds for bias. A model with a level of simplicity comparable to the Black-Leff formalism that would allow complementary quantification of the physico-chemical ligand efficacy would help to better classified compounds and understand the mechanistic basis for differential $G$ protein activation.

Here, we show that the V2 receptor can activate or engage many $\mathrm{G}$ proteins in addition to the previously

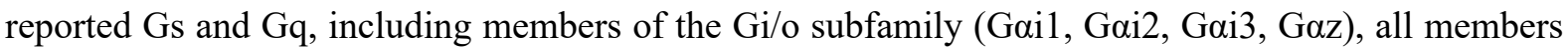

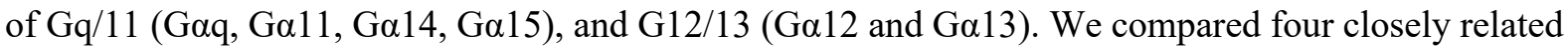
natural and synthetic peptide ligands for V2 receptor: AVP, arginine-vasotocin (a non-mammalian analogue of vasopressin, referred to as vasotocin thereafter), oxytocin and the clinically used vasopressin analogue desmopressin. These peptides differ in only one or two amino acids. As these peptides have widely different affinity towards the receptor that skews the bias factor calculations using the operational model, we developed a simple Michaelis-Menten formalism of G protein activation that can better separate the effects of ligand affinity vs efficacy in the calculation of the signalling bias. Overall, these results suggest that even relatively minor structural changes in the ligand can induce significant signalling bias at the $\mathrm{V} 2$ receptor. 


\section{Results}

\section{Vasopressin $V 2$ receptor recruits members of all $G$ protein families and both $\beta$-arrestins}

We used biosensors based on bioluminescence resonance energy transfer (BRET) to study engagement of different $G$ proteins. The $G \alpha$ subunit of the heterotrimeric $G$ protein was tagged with a mutated variant of Renilla reniformis luciferase RlucII [28] and the G $\gamma$ subunit was N-terminally fused to GFP10 (Fig. 1A). At saturating concentrations of vasopressin, the ligand-mediated $\triangle B R E T$ obtained with several different $\mathrm{G} \alpha$ proteins fused to RlucII was measured. Vasopressin V2 receptor was able to engage

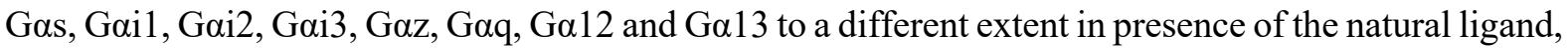

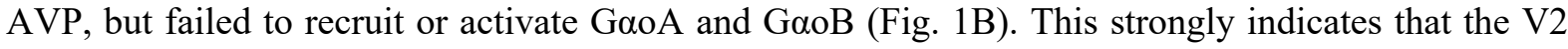
receptor can recruit a broader spectrum of $\mathrm{G}$ proteins beyond the previously reported Gs and $\mathrm{Gq}[10$, 29]. To investigate $V 2 R$ coupling specificity towards the members of the $\mathrm{Gq} / 11$ family, we used protein kinase C (PKC) biosensor [30] in Gq/11/12/13 knock-out cells [29]. This biosensor reports Gq/11family mediated activation of protein kinase $\mathrm{C}$ biosensor that reports on phosphorylation-induced association of forkhead-associated domains selectively binding to PKC-phosphorylated sites (Fig. 1C). Upon addition of AVP, Gq/11/12/13-deficient HEK293 cells showed PKC activation when complemented with $\mathrm{G} \alpha \mathrm{q}, \mathrm{G} \alpha 11, \mathrm{G} \alpha 14$ or $\mathrm{G} \alpha 15$ but not in absence of co-expressed $\mathrm{G} \alpha \mathrm{q}$ family subunits (Fig. 1D). The specific activation of PKC through co-transfected Gq family members shows that V2R not only couples to but also activates all members of the Gq/11 family. Similarly, previously published cAMP activation data have shown that the V2R activates Gs [10]. Using the $\mathrm{G} \alpha-\mathrm{G} \gamma$ biosensor (Fig. 1A) we also tested the change in BRET signal for all recruited $\mathrm{G} \alpha$ subunits in combination with three different G $\gamma$ subunits: G $\gamma 1, \mathrm{G} \gamma 2$ and G $\gamma 5$ (Fig. 1E). We found that all combinations except those of $\mathrm{G} \alpha 12$ with $\mathrm{G} \gamma 2$ and $\mathrm{G} \gamma 5$ lead to a decrease in BRET signal. This may point towards a difference in the interaction of V2R with Ga12 compared to other G $\alpha$ subunits and agrees well with a recent study that reported unproductive complex formation between G 112 and the V2R [31]. In addition to its G protein coupling, the V2R has previously been reported to bind $\beta$-arrestin 1 and 2 equally well [32]. We measured $\beta$-arrestin recruitment using a recently developed enhanced bystander BRET (ebBRET)based biosensor that uses RlucII- $\beta$-arrestin 1 or 2 and a Renilla GFP (rGFP)-tagged CAAX box domain from KRas, which is inserted into the membrane (Fig. 1F) [33]. V2R recruited both $\beta$-arrestins to the same extent (Fig. 1G) at saturating concentrations of AVP, consistent with its classification as Class B for arrestin recruitment [32].

\section{Small differences in peptide ligand sequences give rise to functional selectivity}

For determination of signalling bias among peptide ligands, we compared the signalling of the main endogenous agonist AVP to the vasopressin-analogue desmopressin, the non-mammalian vasopressin analogue vasotocin and the natural agonist oxytocin. The nonapeptides all contain a disulphide bridge and differ in either one or two amino acids (Fig. 2A). We tested the effect of all ligands for Gas, Gai2, $\mathrm{G} \alpha \mathrm{z}, \mathrm{G} \alpha \mathrm{q}, \mathrm{G} \alpha 12$ and $\mathrm{G} \alpha 13$ engagement, protein kinase $\mathrm{C}$ activation through $\mathrm{G} \alpha \mathrm{q}, \mathrm{G} \alpha 11, \mathrm{G} \alpha 14$ or $\mathrm{G} \alpha 15$ and the recruitment of $\beta$-arrestin 1 and 2 . For each effector and ligand combination, we measured concentration-response curves to determine the half-maximal effective concentration (potency, EC50 or pEC50, respectively) (Fig. 2B). In our experiment, the maximal agonist-induced response did not vary across the different ligands tested; all ligands were full agonists for $\beta$-arrestin recruitment and $\mathrm{G}$ protein engagement. However, the potencies (pEC50) differed by almost 2.5 orders of magnitude between AVP and oxytocin (Table 1). The four ligands also significantly differ in their affinity with AVP being the best binder (single digit nanomolar), followed by vasotocin and desmopressin (low twodigit nanomolar) and oxytocin (low micromolar) as determined by radioligand binding [34] (Table 2). The efficacies and potencies of the tested ligands were similar for Gq activation tested using the PKC biosensor versus direct activation with the $\mathrm{G} \alpha-\mathrm{G} \gamma$ biosensor (Table 1). 
We observed three different cases for the high-affinity ligands: First, equal potency for desmopressin and vasotocin, and a higher potency for AVP, which agrees well with the measured affinity values. This is the case for Gi2, Gq, G11, G14, G15, $\beta$-arrestin 1 and 2. Second, equal potency for all three agonists which we observed for Gz and G12. Finally, we observed that the ranked potencies for Gs and G13 were highest for AVP, medium for desmopressin and lowest for vasotocin for Gs; highest for AVP and desmopressin and medium for vasotocin for G13. In addition, we noticed that oxytocin shows a preference towards $G$ protein engagement, while the potency for recruitment of $\beta$-arrestin is clearly lower. None of the ligands showed a preference for one of the two $\beta$-arrestins under the conditions of the study.

We calculated transduction coefficients $\left(\log \left(\tau / K_{\mathrm{A}}\right)\right.$ values) according to the operational model of agonism $[24,25,35]$ to quantify ligand bias. AVP, the main agonist of vasopressin V2 receptor, was chosen as the reference agonist (Table 3). The choice of a reference agonist is necessary to eliminate observational and system bias [21]. The calculated transduction coefficients and their deviation from the reference agonist value $\left(\Delta \log \left(\tau / K_{\mathrm{A}}\right)\right)$ are shown in Fig. 2C. With the exception of Gz and G12, the ability of V2R to elicit response on all other signalling pathways was reduced by a factor of 3-5 for desmopressin and vasotocin. However, for oxytocin it was reduced by about a factor of 100 , suggesting that it is a very poor agonist for V2R. On the other hand, comparison of the ability of the V2R to activate $\mathrm{G}$ proteins (Fig 2) relative to the reported affinity (Table 2) does not indicate that oxytocin is a particularly weak agonist in comparison to other peptides. Considering that all peptides were able to elicit the full amplitude of the biosensor response, the $\tau$ should be relatively large (i.e. $>10$ ) and the difference between the receptor-ligand complex formation and the effector activation response curve should be separated by at least a $\log$ unit [35]. On the other hand, the $\Delta \log \left(\tau / K_{\mathrm{A}}\right)$ values were significantly reduced for the lower-affinity ligands, implying a potential overestimation of the $K_{\mathrm{A}}$ value that reflects the affinity of the agonist for the "active" state of the receptor. This parameter is not the same as the one experimentally observed using ligand binding experiments which typically reflects the affinity of the effector- free receptor if an antagonist is used for determination of the $K \mathrm{~d}$. If an agonist is used to measure it, sometimes a bi-phasic binding curve and a high-affinity state is observed, reflecting an affinity of an agonist for the GPCR-effector complex [36-38]. The high-affinity stage is often observed under conditions of the effector protein present in abundance, however we observed no indications for the biphasic behaviour in our data (Fig 2), nor has it been reported for V2R in previous studies [34]. In the absence of the unusually high concentration of effector proteins, the receptor engages the $\mathrm{G}$ protein for a short time (e.g. $\sim 100 \mathrm{~ms}$ ) during the activation cycle, and is likely to spend most of its time "empty". Shifting the receptor-ligand binding equilibrium takes minutes, given the concentration of the ligand and the kinetics of ligand binding. Therefore, the affinity of the ligand for the receptor is likely to be that of the uncoupled receptor. The apparent inconsistency of the activity analysis for low affinity ligands in comparison to high affinity ones, likely caused by the difficulties in estimating the "functional" affinity of the ligand for the receptor, prompted us to develop an alternative metrics that would link the bias calculations to the experimentally measured ligand affinity and would report changes in receptor activity towards a particular effector at an equal level of receptor saturation by the ligand.

\section{Analysis of the G protein activation using the Michaelis-Menten formalism.}

One of the very promising approaches to describe and quantify the activity of GPCRs receptors in vivo and in vitro is by the enzymatic model $[39,40]$ and, in its simplified form, by the Michaelis-Menten formalism [41, 42]. In this scheme (Fig. 2D), the receptor is considered as an enzyme that catalyses the conversion of substrate to product, i.e. inactive $G$ protein to activated $G$ protein. In the simplest form (one-way activation of the G protein, upper part of the cycle presented in Fig. 2D), this will lead to 
eventual activation of all available $G$ protein. Therefore, it is also important to consider that the activated G protein will be de-activated by alternative mechanisms, e.g. auto-hydrolysis of bound GTP to GDP. The balance between activation and deactivation will determine the concentration of the active $G$ protein present that induces downstream signalling. The use of this model allows us to obtain the intrinsic enzymatic activity of the ligand-receptor complex towards a $G$ protein that can be used for the calculations of intrinsic bias factors. To reliably fit concentration-response curves, it is essential to keep the model simple, with a minimal number of parameters. Therefore, the Michaelis-Menten formalism is preferred to the full enzymatic model as it has the same number of parameters as the operational model.

\section{In silico analysis of the Michaelis-Menten model of $G$ protein activation.}

The first parameter is the concentration of available $G$ protein $\left(S_{0}\right)$ which is related to the second parameter, the Michaelis constant $K_{\mathrm{m}}$. $K_{\mathrm{m}}$ describes the concentration of $\mathrm{G}$ protein at which the $\mathrm{G}$ protein activation by the receptor is half maximal. Another factor is the amount of active receptor, this is a combination of the receptor number and their activity $\left(R_{\mathrm{tot}} k_{\mathrm{cat}}\right)$, high activity can compensate for low receptor numbers and vice versa. The final parameter is the hydrolysis of GTP at the G protein which returns the $\mathrm{G}$ protein to its inactive state. The mathematical description of this model is included in the methods section (Eq. 1-3). To explore and visualise the behaviour of the Michaelis-Menten model and the impact of variation of the parameters, we modelled effects of receptor activity, G protein deactivation, $\mathrm{G}$ protein concentration and the $K_{\mathrm{m}}$ of the $\mathrm{G}$ proteins towards receptor on the observed activation of the $\mathrm{G}$ proteins and, correspondingly, biosensor responses (Fig. 3 and 4). The system needs sufficient $\mathrm{G}$ protein (comparable to the $K_{\mathrm{m}}$ value or above) for the $\mathrm{G}$ protein activation to take place. However, further increase in the $G$ protein concentration does not result in the increase of the potency of the response (i.e. left shift of the curve) as the response (under simulation conditions, see methods for details) follows the ligand binding curve (Fig. S2A). Correspondingly, $K_{\mathrm{m}}$ should be comparable or lower than the concentration of the G protein for the activation to happen (Fig. S2C). The system response is far more sensitive to the changes in the catalytic activity of the activated receptor $\left(k_{\text {cat }}\right)$ and the rate of the $\mathrm{G}$ protein deactivation $\left(k_{\mathrm{h}}\right)$, compared to the changes in $K_{\mathrm{m}}$ or total $\mathrm{G}$ protein concentration $S_{0}$. It must be noted that we combined the receptor density $R_{\text {tot }}$ with the $k_{\text {cat }}$ and modelled variations of $R_{\text {tot }} \cdot k_{\text {cat }}$ parameter as this represents the activity of the receptor pool. The more active the receptor is, the fewer active receptor molecules are needed to reach $50 \%$ of the response, leading to a left-shift of the activation curve relative to the ligand binding. This is encouraging as we can capture the classical "receptor reserve" concept [43]. Contrarily, an increase in the rate of $\mathrm{G}$ protein deactivation $k_{\mathrm{h}}$ directly opposes the activity of the receptor $\left(k_{\text {cat }}\right)$. The faster the activated G protein hydrolyses bound GTP the harder it is to maintain an increased concentration of the active $G$ protein.

\section{Application of Michaelis-Menten model to the experimental data}

To apply this model to available experimental data, further assumptions need to be made. It is important to perform the experiments under the caveat of "all other things being equal". The rate of the active G protein degradation is determined by the "system" (the cells we use for the experiments) and can be assumed to be constant. While we anticipate the $K_{\mathrm{m}}$ values for a given effector to be affected by the nature of the ligand, for a robust response it should still be comparable to the concentration of the $G$ protein and has a limited potential to introduce significant error in the system. Therefore, the $\underline{k}_{\text {cat }}$ is the only significant parameter that determines the behaviour of the system, while all other parameters can be kept constant during the data analysis. As the values of these parameters are not known they are set to one in arbitrary units for the purpose of the fit and are cancelled out by normalisation. Normalisation of the of the obtained $k_{\text {cat }}$ to that of a refence compound 
$B_{\mathrm{mm}}=k_{\mathrm{cat}}($ ligand $) / k_{\mathrm{cat}}($ reference ligand $)$

allows us to define a Michaelis-Menten bias factor $B_{\mathrm{mm}}$. A detailed explanation of the fitting procedure is presented in the methods.

We have applied this model to the BRET-based biosensor data presented above (Fig. 2B), as implemented in the DataFitter laboratory-developed software. Qualitatively, the results of bias calculations according to the Michaelis-Menten model (Fig. 2E) resemble those based on the operational model (Fig. 2C). The most noticeable difference is that the intrinsic activity and $B_{\mathrm{mm}}$ bias factors of oxytocin are comparable to those of other peptides (Fig 2D). This mirrors direct observations of the oxytocin activity as presented on Fig. 2B. The affinity of the ligand does not affect the calculated $k_{\text {cat }}$ or $B_{\mathrm{mm}}$ (bias factors calculated according to the Michaelis-Menten model, see Methods) as opposed to the values derived from the operational model (Fig. 2C). As a result, the differences in the efficacy of the V2R towards G proteins in response to binding of diverse ligands are more accentuated. It is interesting to note that in comparison to AVP, all tested peptides have an increased ability to promote G12 engagement by V2R, but reduced ability to promote V2R-mediated activation of Gq. This parallels the analysis done using the operational model. In addition, oxytocin seems to have significantly reduced ability to promote V2R-mediated activation of Gs and Gi2 as compared to AVP.

Both operational model and Michaelis-Menten methods of calculating signalling bias have provided comparable results. However, Michaelis-Menten model provides more consistent estimates of the differences in signalling bias if the is a large difference in affinity of individual ligands. Taken together, these results strongly suggest that V2R signalling can be readily biased by ligands, and even relatively small structural differences in peptide ligand sequence seem to be sufficient to induce this effect.

\section{Discussion}

\section{V2R promiscuity}

Our data show that V2R can engage members of all $\mathrm{G}$ protein families, not only Gs and Gq as reported previously $[10,29]$. A combination of our PKC activation data and previously published data showing an increase in cAMP levels after V2R activation, points towards activation of Gs and Gq by the V2R. All other G proteins (Gi2, Gz, G12, G13) are at least engaged. A recent paper showed that the V2R engaged G12 unproductively [31], which agrees with the engagement of G12 we observed. In addition, our analysis of the change of BRET signal in dependence of G $\gamma$ subunits (Fig. 1E) shows that G12 is the only $\mathrm{G}$ protein where we observed a decrease in BRET for $\mathrm{G} \gamma 1$ but an increase in BRET for G $\gamma 2$ and $\mathrm{G} \gamma 5$ suggesting that the interaction between the V2R and G12 is not a canonical activation, pointing to a different conformational change between $\mathrm{G} \alpha$ and $\mathrm{G} \beta \gamma$. We also confirmed a strong recruitment of both $\beta$-arrestins [32]. The biological significance of this promiscuity of engagement is beyond the scope of the present study but will warrant future studies. While V2R has a well-documented function in the kidneys where it controls water re-uptake, according to the Protein Atlas (www.proteinatlas.org) [44], it is expressed in practically all tissues, with the exception of the brain and the liver. Most Ga isoforms are also expressed in all tissues. Therefore, V2R has a possibility of interacting with all G proteins in native tissues, suggesting that its promiscuity may be biologically relevant. Dual Gs/Gi coupling has been reported for other receptors such as the $\beta 2$ - and the $\beta 1$ adrenergic receptors $[45,46]$ one possible rationale for simultaneous ctivation of Gs/olf and Gi/o proteins is to fine-tune the cAMP response. However, this does not account for the activation of Gq/11 and recruitment of G12/13 families. Another 
possibility is that the biological process triggered by the V2R may have to be mediated by a combination of signalling pathways, as each individual pathway may only induce a specific subset of cellular events. Recent medium- and large-scale profiling experiments confirmed that promiscuity is rather common among GPCRs [29, 47, 48].

\section{Ligand-induced signalling bias}

The V2R is not only promiscuous in respect to the peptide ligands that activate it but its signalling is also biased by peptide ligands. All four peptides are very similar in sequence (Fig. 2A). They are constrained by a disulphide bridge and they likely adopt the same conformation and the same global binding pose in the V2R ligand binding pocket. Both the affinity of peptides for V2R as well as their signalling properties are affected by amino acid substitutions (Table 2). Any modification of the AVP, be it deamination at the $\mathrm{N}$-terminus or substitutions at position 3 or 8 resulted in decreased ability to activate $\mathrm{Gq}$ and increased ability to recruit (most likely without activation) G12 (Fig. S1). In addition, double substitution of phenylalanine to isoleucine at position 3 and charged arginine at position 8 with hydrophobic leucine in oxytocin reduced the ability of V2R to engage Gs and Gi proteins relative to the other $G$ protein subtypes engaged by the receptor. Similarly, substitution of the L-arginine for Darginine at the same position in desmopressin relative to AVP may be responsible for the reduced Gi engagement compared to Gq. These specific effects of individual substitutions in AVP on peptide signalling properties imply that there must be hot spots in the ligand binding pocket for signalling bias that interact with the residues that were modified. However, in the absence of structural data on peptide binding it is difficult to say which amino acids in the ligand binding pocket are responsible for the signalling bias. Similar observations were reported for oxytocin receptor where small modifications of oxytocin peptide resulted in different signalling preferences [49]. Another extensively documented example are peptide ligands of angiotensin receptor [17, 50,51]. Peptide ligand-induced biased has also been documented in chemokine receptors (reviewed in [52]). It is tempting to speculate that receptorpeptide pairs may have co-evolved as a mechanism to change the activity of ancestral receptors.

\section{Michaelis-Menten quantification of receptor activity}

Previous work has shown applicability of the enzymatic model of GPCR activity [39, 40]. Kenakin and Christopoulos have commented on the apparent similarity between the operational model and the Michaelis-Menten equation [53]. However, despite the apparent mathematical similarity (both functions are hyperbolic), the actual solution for the steady-state concentration of activated G protein is rather different (see methods).

It should also be noted that the simplified Michaelis-Menten model presented here can describe G protein activation but not $\beta$-arrestin recruitment due to the underlying nature of the two processes. First of all, it assumes that the number of receptor molecules is small in comparison to the number of $G$ protein molecules. For most receptors, even in the over-expressed systems, this condition is very likely to be satisfied. Secondly, it also assumes that the activation of the $G$ proteins is non-reversible during the enzymatic step. Given the very high affinity of GTP to the G protein compared to GDP while their concentrations are comparable (0.1-0.5 mM) [54] and the slow hydrolysis-driven deactivation of $\mathrm{G}$ proteins, this condition is also very likely to be satisfied. While RGS proteins may control the rate GTP hydrolysis of Gi and Gq proteins, they only interact with active forms of $\mathrm{G} \alpha$ subunits after they have dissociated from G $\beta \gamma$ after the activation step [55]. Thirdly, it is important to consider the differences between the signals reported by the G protein, PKC and arrestin biosensors. While G proteins are activated directly by the receptors, PKC is activated by several nested enzymatic cycles, requiring a much more complicated model incorporating several Michaelis-Menten reactions. Thus, the data 
reflecting the activation of PKC do not lend themselves to the analysis using simple concentrationresponse curves as many more parameters are needed to define this system quantitatively. In contrast, arrestin biosensors report formation of the receptor-arrestin complex, with a 1:1 stoichiometry. As this is a binding rather than an enzymatic event, it would not be appropriate to analyse the results obtained with these arrestin-recruitment biosensors using Michaelis-Menten formalism. Recent reports suggested that arrestins may be activated and dissociate from the receptors while maintaining the active state, similarly to the G proteins [56]. If this is indeed the case, it may be possible to extend the use of this model onto arrestins. However, different biosensors directly reporting on the activation status of arrestin would have to be used [57-60]. One of the important advantages of the Michaelis-Menten formalism presented here is that it can be extended to describe the kinetics of signalling processes, and not only the steady-state equilibria. The appreciation that signalling may not be an equilibrium process and the importance of considering the kinetics in quantification of bias is growing [61]. We expect that as the biosensor and the data collection methodology improves and that kinetic data becomes routinely recorded, the application of Michaelis-Menten formalism would be of advantage in kinetic bias quantification.

\section{Conclusions}

Our data show that V2R activates selected members of all G protein families and at least engage G12 in response to its native agonist AVP. However, closely related peptides that differ by only one or two amino acids or modification, show divergent signalling bias. This suggests that there are bias hotspots in the ligand binding pocket. We also present a method for quantifying the signalling bias based on Michaelis-Menten formalism that allows reliable separation of the intrinsic activity of the receptor/ligand complex from the effects of the affinity of the ligand to the receptor. Moreover, this method has a potential to be expended to quantify kinetic signalling bias in the future.

\section{Acknowledgements}

This work was supported by the Swiss National Science Foundation grants 135754 and 159748 to DBV; Swiss National Science Foundation Doc.Mobility to FMH; and a Foundation grant (\# 148431) from the Canadian Institute of Health Research (CIHR) to MB. BP was funded by a Fellowship Award from CIHR (2012-2015) and by a Fellowship Award from Diabetes Canada (2016-2018). MB holds a Canada Research chair in Signal Transduction and Molecular Pharmacology. 
Table 1. Potencies (pEC50) and agonist-induced maximal response ("amplitude") of G protein, protein kinase $C$ and $\beta$-arrestin activation, normalised to the maximal response of Gs. Data are mean \pm S.E.M of 2-7 independent experiments done either in triplicates or quadruplicates. Numbers in brackets indicate the fusion site of the luciferase in cases where different sensors were used. Please reduce the precision to the noise of measurement and move the tables into a separate file for the time being. They will need to be after references at submission. What is Emax - it always seems to be around 100. Do we need to report it?

\begin{tabular}{|c|c|c|c|c|c|c|c|c|}
\hline \multirow{2}{*}{ pathway } & \multicolumn{2}{|c|}{ AVP } & \multicolumn{2}{|c|}{ desmopressin } & \multicolumn{2}{|c|}{ vasotocin } & \multicolumn{2}{|c|}{ oxytocin } \\
\hline & pEC50 & response & pEC50 & response & pEC50 & response & pEC50 & response \\
\hline Gs (117) & $8.76 \pm 0.08$ & $100.9 \pm 2.2$ & $8.39 \pm 0.14$ & $92.8 \pm 4.3$ & $8.08 \pm 0.11$ & $85.8 \pm 3.4$ & $6.89 \pm 0.16$ & $86.8 \pm 3.6$ \\
\hline Gi2 & $8.27 \pm 0.08$ & $101.6 \pm 2.8$ & $7.78 \pm 0.14$ & $76.3 \pm 4.0$ & $7.58 \pm 0.17$ & $93.0 \pm 5.8$ & $6.39 \pm 0.18$ & $75.5 \pm 3.9$ \\
\hline Gz & $7.98 \pm 0.09$ & $98.1 \pm 3.7$ & $7.78 \pm 0.09$ & $89.7 \pm 3.3$ & $7.81 \pm 0.10$ & $101.9 \pm 3.5$ & $6.31 \pm 0.09$ & $93.4 \pm 2.8$ \\
\hline Gq & $8.07 \pm 0.06$ & $98.7 \pm 2.5$ & $7.66 \pm 0.06$ & $85.5 \pm 1.9$ & $7.65 \pm 0.06$ & $79.7 \pm 1.7$ & $6.22 \pm 0.07$ & $77.0 \pm 1.9$ \\
\hline G12 & $7.79 \pm 0.21$ & $86.2 \pm 7.2$ & $7.81 \pm 0.25$ & $111.4 \pm 9.2$ & $7.69 \pm 0.22$ & $125.2 \pm 10.7$ & $6.10 \pm 0.16$ & $118.5 \pm 6.4$ \\
\hline G13 & $8.37 \pm 0.12$ & $98.7 \pm 3.8$ & $8.32 \pm 0.13$ & $95.7 \pm 3.7$ & $7.92 \pm 0.15$ & $89.8 \pm 4.1$ & $6.66 \pm 0.11$ & $88.0 \pm 2.7$ \\
\hline PKC (Gq) & $8.69 \pm 0.07$ & $99.7 \pm 2.3$ & $8.01 \pm 0.10$ & $88.8 \pm 3.4$ & $8.06 \pm 0.16$ & $98.9 \pm 5.5$ & $6.25 \pm 0.11$ & $84.4 \pm 3.6$ \\
\hline PKC (G11) & $8.79 \pm 0.09$ & $99.1 \pm 2.9$ & $8.03 \pm 0.09$ & $94.4 \pm 3.2$ & $8.28 \pm 0.12$ & $92.1 \pm 3.8$ & $6.48 \pm 0.09$ & $97.5 \pm 3.0$ \\
\hline PKC (G14) & $8.63 \pm 0.19$ & $97.3 \pm 6.6$ & $7.50 \pm 0.43$ & $79.4 \pm 18.6$ & $7.38 \pm 0.24$ & $142.6 \pm 14.0$ & $5.83 \pm 0.25$ & $96.2 \pm 9.6$ \\
\hline PKC (G15) & $9.26 \pm 0.08$ & $99.5 \pm 2.2$ & $8.43 \pm 0.1$ & $109.2 \pm 3.2$ & $8.49 \pm 0.09$ & $113.2 \pm 3.3$ & $6.77 \pm 0.14$ & $98.1 \pm 4.4$ \\
\hline$\beta$-arrestin 1 & $8.31 \pm 0.05$ & $99.2 \pm 1.9$ & $7.56 \pm 0.05$ & $101.0 \pm 2.3$ & $7.54 \pm 0.06$ & $96.9 \pm 2.2$ & $5.77 \pm 0.04$ & $95.0 \pm 1.6$ \\
\hline$\beta$-arrestin 2 & $8.23 \pm 0.05$ & $99.1 \pm 2.0$ & $7.50 \pm 0.04$ & $98.8 \pm 1.7$ & $7.45 \pm 0.05$ & $93.9 \pm 1.8$ & $5.84 \pm 0.04$ & $95.1 \pm 1.7$ \\
\hline
\end{tabular}

Table 2. Dependence of $\log B_{\mathrm{mm}}$ values on ligand amino-acid sequence, using AVP as the reference peptide. F3L: exchange of a phenylalanine at position 3 for a leucine, R8L: exchange of an arginine at position 8 for a leucine, $R(L) 8 R(D)$ - exchange of the L- for D-arginine at position8.

\begin{tabular}{|c|c|c|c|c|c|c|c|c|c|c|c|}
\hline name & $\begin{array}{l}\text { deami } \\
- \\
\text { nation }\end{array}$ & $\begin{array}{l}\text { F3 } \\
\text { L }\end{array}$ & $\begin{array}{l}\text { R8 } \\
\mathrm{L}\end{array}$ & $\begin{array}{l}\mathrm{R}(\mathrm{L}) \\
8 \\
\mathrm{R}(\mathrm{D})\end{array}$ & $\begin{array}{l}\log K_{\mathrm{i}} \\
{[34]}\end{array}$ & $\begin{array}{l}\text { Gs } \\
\log B_{\mathrm{mm}}\end{array}$ & $\begin{array}{l}\mathrm{Gi} 2 \\
\log B_{\mathrm{mm}}\end{array}$ & $\begin{array}{l}\mathrm{Gz} \\
\log B_{\mathrm{mm}}\end{array}$ & $\begin{array}{l}\mathrm{Gq} \\
\log B_{\mathrm{mm}}\end{array}$ & $\begin{array}{l}\mathrm{G} 12 \\
\log B_{\mathrm{mm}}\end{array}$ & $\begin{array}{l}\mathrm{G} 13 \\
\log B_{\mathrm{mm}}\end{array}$ \\
\hline AVP & 0 & 0 & 0 & 0 & -8.97 & 0 & 0 & 0 & 0 & 0 & 0 \\
\hline $\begin{array}{l}\text { desmopressi } \\
\text { n }\end{array}$ & 1 & 0 & 0 & 1 & -7.51 & 0.01 & 0.08 & 0.05 & -0.1 & 0.1 & -0.1 \\
\hline vasotocin & 0 & 1 & 0 & 0 & -7.6 & 0.02 & 0.01 & 0.02 & 0.11 & 0.1 & -0.02 \\
\hline oxytocin & 0 & 1 & 1 & 0 & -5.81 & 0.17 & 0.17 & 0.05 & 0.13 & 0.1 & -0.05 \\
\hline
\end{tabular}

Table 3. Transduction coefficients $\left(\log \left(\tau / \mathrm{K}_{\mathrm{A}}\right)\right)$ and $\Delta \log \left(\tau / K_{\mathrm{A}}\right)$ with AVP as reference ligand. Data are mean \pm S.E.M of 2-7 independent experiments done either in triplicates or quadruplicates.

\begin{tabular}{|c|c|c|c|c|c|c|c|}
\hline \multirow[t]{2}{*}{ pathway } & \multirow{2}{*}{$\frac{\mathrm{AVP}}{\log \left(\tau / K_{\mathrm{A}}\right)}$} & \multicolumn{2}{|c|}{ desmopressin } & \multicolumn{2}{|c|}{ vasotocin } & \multicolumn{2}{|c|}{ oxytocin } \\
\hline & & $\log \left(\tau / K_{\mathrm{A}}\right)$ & $\Delta \log \left(\tau / K_{\mathrm{A}}\right)$ & $\log \left(\tau / K_{\mathrm{A}}\right)$ & $\Delta \log \left(\tau / K_{\mathrm{A}}\right)$ & $\log \left(\tau / K_{\mathrm{A}}\right)$ & $\Delta \log \left(\tau / K_{\mathrm{A}}\right)$ \\
\hline Gs (67) & $8.49 \pm 0.20$ & $8.82 \pm 0.2$ & $0.33 \pm 0.28$ & $8.04 \pm 0.21$ & $-0.45 \pm 0.29$ & $6.92 \pm 0.22$ & $-1.57 \pm 0.30$ \\
\hline Gs (117) & $8.81 \pm 0.11$ & $8.20 \pm 0.11$ & $-0.61 \pm 0.15$ & $7.76 \pm 0.11$ & $-1.05 \pm 0.16$ & $6.76 \pm 0.13$ & $-2.06 \pm 0.17$ \\
\hline Gi2 & $8.30 \pm 0.14$ & $7.43 \pm 0.17$ & $-0.87 \pm 0.22$ & $7.54 \pm 0.14$ & $-0.76 \pm 0.20$ & $6.33 \pm 0.21$ & $-1.97 \pm 0.25$ \\
\hline $\mathbf{G z}$ & $7.97 \pm 0.11$ & $7.67 \pm 0.11$ & $-0.30 \pm 0.16$ & $7.80 \pm 0.09$ & $-0.18 \pm 0.14$ & $6.18 \pm 0.11$ & $-1.79 \pm 0.15$ \\
\hline Gq & $8.04 \pm 0.04$ & $7.59 \pm 0.06$ & $-0.45 \pm 0.07$ & $7.66 \pm 0.10$ & $-0.38 \pm 0.11$ & $6.09 \pm 0.08$ & $-1.95 \pm 0.11$ \\
\hline G12 & $7.54 \pm 0.25$ & $7.88 \pm 0.20$ & $0.34 \pm 0.32$ & $7.74 \pm 0.22$ & $0.20 \pm 0.33$ & $6.12 \pm 0.18$ & $-1.42 \pm 0.31$ \\
\hline G13 & $8.57 \pm 0.11$ & $8.56 \pm 0.12$ & $-0.01 \pm 0.16$ & $7.95 \pm 0.12$ & $-0.62 \pm 0.16$ & $6.67 \pm 0.12$ & $-1.90 \pm 0.16$ \\
\hline $\operatorname{PKC}(\mathrm{Gq})$ & $8.68 \pm 0.08$ & $7.97 \pm 0.11$ & $-0.71 \pm 0.13$ & $8.18 \pm 0.10$ & $-0.50 \pm 0.12$ & $6.19 \pm 0.12$ & $-2.49 \pm 0.14$ \\
\hline
\end{tabular}




\begin{tabular}{llllllll}
\hline PKC (G11) & $8.75 \pm 0.07$ & $8.04 \pm 0.08$ & $-0.71 \pm 0.11$ & $8.32 \pm 0.09$ & $-0.44 \pm 0.11$ & $6.44 \pm 0.08$ & $-2.32 \pm 0.11$ \\
PKC (G14) & $8.65 \pm 0.33$ & $7.41 \pm 0.43$ & $-1.24 \pm 0.54$ & $7.51 \pm 0.15$ & $-1.14 \pm 0.36$ & $6.01 \pm 0.36$ & $-2.64 \pm 0.49$ \\
PKC (G15) & $9.16 \pm 0.10$ & $8.52 \pm 0.09$ & $-0.65 \pm 0.13$ & $8.51 \pm 0.09$ & $-0.65 \pm 0.13$ & $6.64 \pm 0.10$ & $-2.53 \pm 0.14$ \\
$\boldsymbol{\beta}$-arrestin 1 & $8.30 \pm 0.05$ & $7.58 \pm 0.05$ & $-0.72 \pm 0.07$ & $7.50 \pm 0.05$ & $-0.80 \pm 0.07$ & $5.76 \pm 0.05$ & $-2.54 \pm 0.07$ \\
$\boldsymbol{\beta}$-arrestin 2 & $8.22 \pm 0.03$ & $7.52 \pm 0.04$ & $-0.69 \pm 0.05$ & $7.49 \pm 0.05$ & $-0.73 \pm 0.05$ & $5.85 \pm 0.04$ & $-2.37 \pm 0.05$ \\
\hline
\end{tabular}

Table 4. Comparison of bias between pathways with Gs as a reference $(\Delta \Delta \log (\tau / \mathrm{KA})$ values $)$ and bias factors.

\begin{tabular}{lrrrrrr}
\hline pathway & \multicolumn{2}{c}{ desmopressin } & \multicolumn{2}{c}{ vasotocin } & \multicolumn{2}{c}{ oxytocin } \\
\cline { 2 - 7 } & $\Delta \Delta \log \left(\tau / K_{\mathrm{A}}\right)$ & \multicolumn{1}{c}{ bias factor } & $\Delta \Delta \log \left(\tau / K_{\mathrm{A}}\right)$ & \multicolumn{1}{c}{ bias factor } & $\Delta \Delta \log \left(\tau / K_{\mathrm{A}}\right)$ & bias factor \\
Gi2 & $-0.26 \pm 0.27$ & 0.55 & $0.28 \pm 0.26$ & 1.93 & $0.08 \pm 0.31$ & 1.21 \\
$\mathbf{G z}$ & $0.32 \pm 0.22$ & 2.07 & $0.87 \pm 0.21$ & 7.46 & $0.27 \pm 0.23$ & 1.86 \\
$\mathbf{G q}$ & $0.17 \pm 0.17$ & 1.47 & $0.67 \pm 0.19$ & 4.69 & $0.11 \pm 0.21$ & 1.28 \\
$\mathbf{G 1 2}$ & $0.96 \pm 0.36$ & 9.06 & $1.25 \pm 0.37$ & 17.58 & $0.64 \pm 0.35$ & 4.33 \\
$\mathbf{G 1 3}$ & $0.60 \pm 0.22$ & 3.99 & $0.43 \pm 0.23$ & 2.69 & $0.16 \pm 0.24$ & 1.44 \\
PKC (Gq) & $-0.09 \pm 0.20$ & 0.80 & $0.55 \pm 0.20$ & 3.52 & $-0.43 \pm 0.22$ & 0.37 \\
PKC (G11) & $-0.10 \pm 0.19$ & 0.79 & $0.61 \pm 0.19$ & 4.09 & $-0.26 \pm 0.20$ & 0.55 \\
PKC (G14) & $-0.63 \pm 0.56$ & 0.24 & $-0.09 \pm 0.40$ & 0.81 & $-0.59 \pm 0.52$ & 0.26 \\
PKC (G15) & $-0.03 \pm 0.20$ & 0.93 & $0.39 \pm 0.10$ & 2.48 & $-0.47 \pm 0.22$ & 0.34 \\
$\boldsymbol{\beta}$-arrestin 1 & $-0.11 \pm 0.17$ & 0.78 & $0.25 \pm 0.17$ & 1.76 & $-0.48 \pm 0.18$ & 0.33 \\
$\boldsymbol{\beta}$-arrestin 2 & $-0.08 \pm 0.16$ & 0.84 & $0.32 \pm 0.17$ & 2.09 & $-0.31 \pm 0.18$ & 0.49 \\
\hline
\end{tabular}

\section{Materials and Methods}

Vasopressin $V 2$ receptor ligands

[Arg ${ }^{8}$ ]-Vasopressin (AVP) (Cys-Tyr-Phe-Gln-Asn-Cys-Pro-Arg-Gly-NH ${ }_{2}$; disulphide bridge: Cys $^{1}$-Cys $^{6}, 1085.25$ g/mol), Desmopressin acetate (deamino-Cys-Tyr-Phe-Gln-Asn-Cys-ProD-Arg-Gly- $\mathrm{NH}_{2}$; disulphide bridge: $\mathrm{Cys}^{1}-\mathrm{Cys}^{6}, 1069.24 \mathrm{~g} / \mathrm{mol}$ ) and oxytocin acetate (Cys-TyrPhe-Gln-Asn-Cys-Pro-Arg-Gly-NH ${ }_{2}$; disulphide bridge: Cys ${ }^{1}-\mathrm{Cys}^{6}{ }^{6}, 1085.25 \mathrm{~g} / \mathrm{mol}$ ) were purchased from Genemed Synthesis Inc. (San Antonio, TX, USA) and [Arg8]-Vasotocin acetate (Cys-Tyr-Ile-Gln-Asn-Cys-Pro-Arg-Gly-NH 2 , disulphide bridge: $\mathrm{Cys}^{1}{ }^{1} \mathrm{Cys}^{6}$, 1050.22 $\mathrm{g} / \mathrm{mol}$ ) was from Sigma-Aldrich (Ontario, Canada).

\section{Biosensor constructs}

Our biosensor measurements are based on BRETassay technology [62]. For the plasmids encoding for RlucII-G $\alpha$ constructs, constructs were prepared using flexible NAAIRS linkers to insert Renilla luciferase (RlucII) into the coding sequence of human Ga versions. RlucII was inserted between amino acids $\mathrm{Asp}^{94}$ and $\mathrm{Phe}^{95}$ of Gaz using NAAIRSTRPRCT and TRPRCTNAAIRS as linkers. The Gai1, 2 and 3 RlucII fusions contain a duplication of the respective loop where the RlucII was inserted; namely DSA and RLKIDFG for Gai1, ADPS and NLQIDF for Gai2, EAA and RLKIDFG for Gai3, always followed and preceded by NAAIRS, respectively. Insertion positions were $\mathrm{Gly}^{96} / \mathrm{Asp}^{97}$ for Gai1, $\mathrm{Phe}^{95} / \mathrm{Ala}^{96}$ for Gai2 and $\mathrm{Gly}^{96} / \mathrm{Glu}^{97}$ for Gai3. The GaoA construct was described previously (Richard-Lalonde et al., 2013). G $\gamma 1$, G $\gamma 2$ and G $\gamma 5$ were N-terminally tagged with GFP10 as described (Galés et al., 2006) and $\beta$ arrestin 1 and 2 were N-terminally fused to RlucII (Perroy et al., 2004). 


\section{Cell culture and transfection}

Human embryonic kidney (HEK) 293SL cells were transiently cotransfected with Flag-V2R, different RlucII-G $\alpha$ variants, G $\beta 1$ and GFP10-G $\gamma 1$ for G protein activation measurements and with Flag-V2R, RlucII- $\beta$-arrestin1 or 2 and CAAX-GFP10 for $\beta$-arrestin recruitment measurements. For Protein kinase C (PKC) activation, HEK293 $\Delta \mathrm{Gq} / 11 / 12 / 13$ cells were transiently co-transfected with Flag-V2R and unimolecular PKC biosensor for controls and with Flag-V2R, unimolecular PKC biosensor and either Gq, G11, G14 or G15 for activation experiments. The HEK293 $\Delta \mathrm{Gq} / 11 / 12 / 13$ cells were obtained by CRISPR-Cas9 technology [29]. Linear $25 \mathrm{kDa}$ polyethyleneimine (PEI) (Polysciences Inc.) was prepared in phosphatebuffered saline (PBS) (Multicell) (PEI:DNA ratio 3:1). Per 0.24 million HEK293SL cells, $1 \mu \mathrm{g}$ DNA was used. The cells were seeded into white Cellstar ${ }^{\circledR}$ PS 96-well cell culture plates (Greiner Bio-One, Germany) at a density of 20,000 cells per well and grown for $48 \mathrm{~h}$ at $37^{\circ} \mathrm{C}$ with $5 \% \mathrm{CO}_{2}$.

\section{Biosensor measurements}

$48 \mathrm{~h}$ after transfection the 96-well plates were washed with $200 \mu 1 \mathrm{PBS} /$ well and $90 \mu 1$ of Tyrode's buffer ( $\mathrm{NaCl} 137 \mathrm{mM}, \mathrm{KCl} 0.9 \mathrm{mM}, \mathrm{MgCl}_{2} 1 \mathrm{mM}, \mathrm{NaHCO}_{3} 11.9 \mathrm{mM}, \mathrm{NaH}_{2} \mathrm{PO}_{4}$ $3.6 \mathrm{mM}$, Hepes $25 \mathrm{mM}$, glucose $5.5 \mathrm{mM}, \mathrm{CaCl}_{2} 1 \mathrm{mM} \mathrm{pH} 7.4$ ) were added and the cells were stored at $37^{\circ} \mathrm{C}$ with $5 \% \mathrm{CO}_{2}$ for $2 \mathrm{~h}$ prior to the measurement. For the measurement the plates are incubated with $10 \mu \mathrm{l}$ ligand or vehicle per well for $5 \mathrm{~min}$, then $10 \mu 1$ coelenterazine $400 \mathrm{a}$ (DeepBlueC) $2.5 \mu \mathrm{M}$ final were added. After further $5 \mathrm{~min}$ of incubation, luminescence and GFP10 counts were measured at 410 and $515 \mathrm{~nm}$, respectively, in a Synergy Neo (Biotek) plate reader using $0.4 \mathrm{~s}$ integration time.

\section{Preparation of ligands}

All ligands were prepared in $0.1 \%(\mathrm{w} / \mathrm{v}) \mathrm{BSA}$, stock solutions were stored at $-20^{\circ} \mathrm{C}$ while dilutions for the experiments were stored at $4^{\circ} \mathrm{C}$. All ligand dilutions for experiments were used within 4 days of preparation.

\section{Data analysis}

Data analysis was done in GraphPad Prism version 6.05 for Windows (GraphPad Software, La Jolla California USA, www.graphpad.com). All data points were normalised to the maximal response obtained with AVP and expressed as percentage. Values are given \pm S.E.M for $n$ experiments. Bias factors were calculated according to the operational model (Black and Leff, 1983; Gregory et al., 2010). The final equation used for non-linear curve fitting is:

$$
E=\text { basal }+\frac{E_{\mathrm{m}}-\text { basal }}{1+\left(\frac{\frac{[\mathrm{A}]}{10^{\log K_{\mathrm{A}}}}+1}{10^{\log R} \times[\mathrm{A}]}\right)^{n}}
$$

where $E$ is the ligand effect, [A] is the agonist concentration, $E_{\mathrm{m}}$ is the maximal response of the system, basal is the signal in absence of ligand, $K_{\mathrm{A}}$ is the functional equilibrium constant, $R$ is the transduction coefficient $\frac{\tau}{K_{\mathrm{A}}}$ where $\tau$ is an index for the efficacy of the agonist and $n$ is 
the slope (Evans et al., 2011; Kenakin et al., 2012; Kenakin and Christopoulos, 2013; van der Westhuizen et al., 2014).

\section{Michaelis-Menten based description of the G protein activation by a GPCR}

In the enzymatic model of GPCR activity, the G protein activation is catalysed by the receptor and is dependent on the agonist binding $[39,40]$. The concentration of the active agonist-bound receptor $R(L)$ is described by a binding isotherm:

$R(L)=R_{\mathrm{tot}} \cdot L /\left(K_{\mathrm{d}}+L\right) \quad(1)$

where $R_{\text {tot }}$ is the total concentration of the receptor, $L$ is ligand concentration and $K_{\mathrm{d}}$ is the ligand dissociation constant.

A minimal system (Fig. 2D) considers the formation of product ( $\mathrm{P}$, activated $\mathrm{G}$ protein, $\mathrm{G} \alpha-\mathrm{GTP}$ ) as a function of agonist-bound receptor concentration $R(L)$, that is described by the Eq. 1 above, its catalytic activity rate constant $k_{\text {cat, }}$ as well as the Michaelis constant $K_{\mathrm{m}}$ for the $\mathrm{G}$ protein-receptor interaction. The rate of deactivation of the activated $G$ protein $(\mathrm{P})$ into inactive $\mathrm{G}$ protein $(\mathrm{S})$ depends on the concentration of product and the hydrolysis rate constant $k_{\mathrm{h}}$ of GTP to GDP at the Ga subunit.

$\frac{d[\mathrm{P}]}{d t}=\frac{R(L) \cdot k_{\mathrm{cat}} \cdot[\mathrm{S}]}{K_{\mathrm{m}}+[\mathrm{S}]}-k_{\mathrm{h}} \cdot[\mathrm{P}]$

Considering the deactivation of the active G protein via GTP hydrolysis is an important feature of this model as it determines the concentration of the activated $\mathrm{G}$ protein.

At steady-state conditions there is an analytical solution yielding the concentration of activated $\mathrm{G}$ protein $[\mathrm{P}]$ as a function of the total (i.e., inactive and active combined) concentration of the $\mathrm{G}$ protein, $S_{0}$.

$[\mathrm{P}]=S_{0}-\frac{-\left(\frac{R(L) k_{\mathrm{cat}}}{k_{\mathrm{h}}}-S_{0}+K_{\mathrm{m}}\right)+\sqrt{\left(\frac{R(L) k_{\mathrm{cat}}}{k_{\mathrm{h}}}-S_{0}+K_{m}\right)^{2}+4 K_{\mathrm{m}} S_{0}}}{2}$

From the mathematical point of view, what matters for the steady-state solution is the apparent catalytic activity of the receptor-ligand complex in activating a $\mathrm{G}$ protein in a given system:

$A_{\text {cat }}=R(L) \cdot k_{\text {cat }} / k_{\mathrm{h}},(4)$

where $R(L)$ and $k_{\text {cat }}$ depend on the ligand affinity and concentration as well as the ligand signalling properties while $k_{\mathrm{h}}$ depends on the $\mathrm{G}$ protein and other system parameters.

Subsequently, the Eq. 3 could be simplified to

$[\mathrm{P}]=S_{0}-\frac{-\left(A_{\mathrm{cat}}-S_{0}+K_{\mathrm{m}}\right)+\sqrt{\left(A_{\mathrm{cat}}-S_{0}+K_{\mathrm{m}}\right)^{2}+4 K_{\mathrm{m}} S_{0}}}{2}$ 
Correspondingly, the steady-state bias factor between two ligands for a given system can be expressed as

$B_{\mathrm{mm}}=k_{\mathrm{cat}}($ ligand $) / k_{\mathrm{cat}}($ reference ligand $)=A_{\mathrm{cat}}($ ligand $) / A_{\text {cat }}($ reference ligand $)$

at the concentration of the ligand that results in the same occupancy of the receptor.

While in our experiments the values of $S_{0}$ and $K_{\mathrm{m}}$ are not known, it is their value relative to the $A_{\text {cat }}$ that would define the shape of the response curve. Therefore, for data fitting purposes we set their values to 1 and only interpret changes relative to the reference ligand. The data for individual ligands were fitted simultaneously to a MM model described above using the in house DataFitter software (D. Veprintsev).

\section{Simulations of Michaelis-Menten based description of the G protein activation by a GPCR}

All simulations were performed using Cell Designer [63]. The value of the parameters of the system ( $R_{\mathrm{tot}}, k_{\mathrm{cat}}, k_{\mathrm{h}}, K_{\mathrm{m}}$ and $S_{0}$ ) were fixed to 1 , while the value of the parameter presented on the Y axis and the ligand concentration were varied. 


\section{References}

1. Rask-Andersen, M., S. Masuram, and H.B. Schiöth, The Druggable Genome: Evaluation of Drug Targets in Clinical Trials Suggests Major Shifts in Molecular Class and Indication. Annual Review of Pharmacology and Toxicology, 2014. 54(1): p. 9-26.

2. Downes, G.B. and N. Gautam, The G Protein Subunit Gene Families. Genomics, 1999. 62(3): p. $544-552$.

3. Simon, M., M. Strathmann, and N. Gautam, Diversity of $G$ proteins in signal transduction. Science, 1991. 252(5007): p. 802-808.

4. $\quad$ Ashkenazi, A., et al., An M2 muscarinic receptor subtype coupled to both adenylyl cyclase and phosphoinositide turnover. Science, 1987. 238(4827): p. 672-675.

5. Cotecchia, S., et al., Multiple second messenger pathways of alpha-adrenergic receptor subtypes expressed in eukaryotic cells. J Biol Chem, 1990. 265(1): p. 63-9.

6. Fargin, A., et al., Effector coupling mechanisms of the cloned 5-HT1A receptor. J Biol Chem, 1989. 264(25): p. 14848-52.

7. Gudermann, T., M. Birnbaumer, and L. Birnbaumer, Evidence for dual coupling of the murine luteinizing hormone receptor to adenylyl cyclase and phosphoinositide breakdown and Ca2+ mobilization. Studies with the cloned murine luteinizing hormone receptor expressed in L cells. J Biol Chem, 1992. 267(7): p. 4479-88.

8. Vallar, L., et al., Differential coupling of dopaminergic D2 receptors expressed in different cell types. Stimulation of phosphatidylinositol 4,5-bisphosphate hydrolysis in LtK- fibroblasts, hyperpolarization, and cytosolic-free Ca2+ concentration decrease in GH4C1 cells. J Biol Chem, 1990. 265(18): p. 10320-6.

9. Van Sande, J., et al., Thyrotropin activates both the cyclic AMP and the PIP2 cascades in CHO cells expressing the human cDNA of TSH receptor. Mol Cell Endocrinol, 1990. 74(1): p. R1-6.

10. Zhu, X., et al., Dual signaling potential is common among Gs-coupled receptors and dependent on receptor density. Mol Pharmacol, 1994. 46(3): p. 460-9.

11. Crawford, K.W., E.A. Frey, and T.E. Cote, Angiotensin II receptor recognized by DuP753 regulates two distinct guanine nucleotide-binding protein signaling pathways. Mol Pharmacol, 1992. 41(1): p. 154-62.

12. Azzi, M., et al., Beta-arrestin-mediated activation of MAPK by inverse agonists reveals distinct active conformations for G protein-coupled receptors. Proc Natl Acad Sci USA, 2003. 100(20): p. 11406-11.

13. Galandrin, S., G. Oligny-Longpre, and M. Bouvier, The evasive nature of drug efficacy: implications for drug discovery. Trends Pharmacol Sci, 2007. 28(8): p. 423-30.

14. Jarpe, M.B., et al., [D-Arg1,D-Phe5,D-Trp7,9,Leu11]Substance P acts as a biased agonist toward neuropeptide and chemokine receptors. J Biol Chem, 1998. 273(5): p. 3097-104.

15. Kenakin, T. and L.J. Miller, Seven transmembrane receptors as shapeshifting proteins: the impact of allosteric modulation and functional selectivity on new drug discovery. Pharmacol Rev, 2010. 62(2): p. 265-304.

16. MacKinnon, A.C., et al., Bombesin and substance P analogues differentially regulate G-protein coupling to the bombesin receptor. Direct evidence for biased agonism. J Biol Chem, 2001. 276(30): p. 28083-91.

17. Wei, H., et al., Independent beta-arrestin 2 and $G$ protein-mediated pathways for angiotensin II activation of extracellular signal-regulated kinases 1 and 2. Proc Natl Acad Sci U S A, 2003. 100(19): p. 10782-7.

18. Bohn, L.M., Enhanced Morphine Analgesia in Mice Lacking-Arrestin 2\&nbsp. Science, 1999. 286(5449): p. 2495-2498.

19. Bohn, L.M., et al., Mu-opioid receptor desensitization by beta-arrestin-2 determines morphine tolerance but not dependence. Nature, 2000. 408(6813): p. 720-3.

20. Rankovic, Z., T.F. Brust, and L.M. Bohn, Biased agonism: An emerging paradigm in GPCR drug discovery. Bioorg Med Chem Lett, 2016. 26(2): p. 241-50. 
bioRxiv preprint doi: https://doi.org/10.1101/2021.01.28.427950; this version posted January $28,2021$. The copyright holder for this preprint (which was not certified by peer review) is the author/funder, who has granted bioRxiv a license to display the preprint in perpetuity. It is made available under aCC-BY 4.0 International license.

21. Kenakin, T. and A. Christopoulos, Signalling bias in new drug discovery: detection, quantification and therapeutic impact. Nature reviews. Drug discovery, 2013. 12(3): p. 20516.

22. Benredjem, B., et al., Exploring use of unsupervised clustering to associate signaling profiles of GPCR ligands to clinical response. Nature Communications, 2019. 10(1).

23. Smith, J.S., R.J. Lefkowitz, and S. Rajagopal, Biased signalling: from simple switches to allosteric microprocessors. Nature Reviews Drug Discovery, 2018. 17(4): p. 243-260.

24. Black, J.W. and P. Leff, Operational models of pharmacological agonism. Proc R Soc Lond B Biol Sci, 1983. 220(1219): p. 141-62.

25. Kenakin, T., et al., A simple method for quantifying functional selectivity and agonist bias. ACS Chem Neurosci, 2012. 3(3): p. 193-203.

26. Rajagopal, S., et al., Quantifying Ligand Bias at Seven-Transmembrane Receptors. Molecular Pharmacology, 2011. 80(3): p. 367-377.

27. Heitzler, D., et al., Competing G protein-coupled receptor kinases balance G protein and betaarrestin signaling. Mol Syst Biol, 2012. 8: p. 590.

28. Leduc, M., et al., Functional Selectivity of Natural and Synthetic Prostaglandin EP4 Receptor Ligands. Journal of Pharmacology and Experimental Therapeutics, 2009. 331(1): p. 297-307.

29. Inoue, A., et al., Illuminating G-Protein-Coupling Selectivity of GPCRs. Cell, 2019.

30. Namkung, Y., et al., Functional selectivity profiling of the angiotensin II type 1 receptor using pathway-wide BRET signaling sensors. Science Signaling, 2018. 11(559).

31. Okashah, N., et al., Agonist-induced formation of unproductive receptor-G12 complexes. Proc Natl Acad Sci U S A, 2020.

32. Oakley, R.H., et al., Differential affinities of visual arrestin, beta arrestin1, and beta arrestin2 for $G$ protein-coupled receptors delineate two major classes of receptors. J Biol Chem, 2000. 275(22): p. 17201-10.

33. Namkung, Y., et al., Monitoring G protein-coupled receptor and beta-arrestin trafficking in live cells using enhanced bystander BRET. Nat Commun, 2016. 7: p. 12178.

34. Chini, B., et al., Tyr115 is the key residue for determining agonist selectivity in the Vla vasopressin receptor. EMBO J, 1995. 14(10): p. 2176-82.

35. Black, J.W., et al., An operational model of pharmacological agonism: the effect of E/[A] curve shape on agonist dissociation constant estimation. Br J Pharmacol, 1985. 84(2): p. 561-71.

36. De Lean, A., J.M. Stadel, and R.J. Lefkowitz, A ternary complex model explains the agonistspecific binding properties of the adenylate cyclase-coupled beta-adrenergic receptor. Journal of Biological Chemistry, 1980. 255(15): p. 7108-7117.

37. DeVree, B.T., et al., Allosteric coupling from $G$ protein to the agonist-binding pocket in GPCRs. Nature, 2016. 535(7610): p. 182-6.

38. Staus, D.P., et al., Allosteric nanobodies reveal the dynamic range and diverse mechanisms of G-protein-coupled receptor activation. Nature, 2016. 535(7612): p. 448-452.

39. Waelbroeck, M., L. Boufrahi, and S. Swillens, Seven helix receptors are enzymes catalysing $G$ protein activation. What is the agonist Kact? J Theor Biol, 1997. 187(1): p. 15-37.

40. Roberts, D.J. and M. Waelbroeck, G protein activation by G protein coupled receptors: ternary complex formation or catalyzed reaction? Biochem Pharmacol, 2004. 68(5): p. 799-806.

41. Ernst, O.P., et al., Monomeric G protein-coupled receptor rhodopsin in solution activates its $G$ protein transducin at the diffusion limit. Proc Natl Acad Sci U S A, 2007. 104(26): p. 1085964.

42. Maeda, S., et al., Crystallization scale preparation of a stable GPCR signaling complex between constitutively active rhodopsin and G-protein. PLoS ONE, 2014. 9(6): p. e98714.

43. Kenakin, T.P., A pharmacology primer : techniques for more effective and strategic drug discovery. Fourth edition. ed. 2014, Amsterdam ; Boston: Elsevier Academic Press. xix, 430 pages.

44. Uhlen, M., et al., Tissue-based map of the human proteome. Science, 2015. 347(6220): p. 1260419-1260419.

45. Xiao, R.P., X. Ji, and E.G. Lakatta, Functional coupling of the beta 2-adrenoceptor to a pertussis toxin-sensitive G protein in cardiac myocytes. Mol Pharmacol, 1995. 47(2): p. 322-9. 
46. Lukasheva, V., et al., Signal profiling of the $\beta 1 A R$ reveals coupling to novel signalling pathways and distinct phenotypic responses mediated by $\beta 1 A R$ and $\beta 2 A R$. Scientific Reports, 2020. 10(1).

47. Okashah, N., et al., Variable G protein determinants of GPCR coupling selectivity. Proceedings of the National Academy of Sciences, 2019.

48. Avet, C., et al., Selectivity Landscape of 100 Therapeutically Relevant GPCR Profiled by an Effector Translocation-Based BRET Platform. BioRxiv, 2020.

49. Busnelli, M., et al., Functional selective oxytocin-derived agonists discriminate between individual G protein family subtypes. J Biol Chem, 2012. 287(6): p. 3617-29.

50. Namkung, Y., et al., Functional selectivity profiling of the angiotensin II type 1 receptor using pathway-wide BRET signaling sensors. Sci Signal, 2018. 11(559).

51. Ahn, S., et al., Differential kinetic and spatial patterns of beta-arrestin and G protein-mediated ERK activation by the angiotensin II receptor. J Biol Chem, 2004. 279(34): p. 35518-25.

52. Steen, A., et al., Biased and G Protein-Independent Signaling of Chemokine Receptors. Frontiers in Immunology, 2014. 5.

53. Kenakin, T. and A. Christopoulos, Measurements of ligand bias and functional affinity. Nat Rev Drug Discov, 2013. 12(6): p. 483-483.

54. Traut, T.W., Physiological concentrations of purines and pyrimidines. Molecular and Cellular Biochemistry, 1994. 140(1): p. 1-22.

55. Tesmer, J.J.G., Chapter 4 Structure and Function of Regulator of G Protein Signaling Homology Domains, in Molecular Biology of RGS Proteins. 2009. p. 75-113.

56. Eichel, K., et al., Catalytic activation of $\beta$-arrestin by GPCRs. Nature, 2018. 557(7705): p. 381386.

57. Charest, P.G., S. Terrillon, and M. Bouvier, Monitoring agonist-promoted conformational changes of beta-arrestin in living cells by intramolecular BRET. EMBO Rep, 2005. 6(4): p. 334-40.

58. Zimmerman, B., et al., Differential beta-arrestin-dependent conformational signaling and cellular responses revealed by angiotensin analogs. Sci Signal, 2012. 5(221): p. ra33.

59. Lee, M.H., et al., The conformational signature of beta-arrestin2 predicts its trafficking and signalling functions. Nature, 2016. 531(7596): p. 665-8.

60. Nuber, S., et al., beta-Arrestin biosensors reveal a rapid, receptor-dependent activation/deactivation cycle. Nature, 2016. 531(7596): p. 661-4.

61. Klein Herenbrink, C., et al., The role of kinetic context in apparent biased agonism at GPCRs. Nature Communications, 2016. 7(1).

62. Dionne, P., et al., BRET2: efficient energy transfer from Renilla luciferase to GFP2 to measure protein-protein interactions and intracellular signaling events in live cells. , in Luminescence biotechnology: instruments and applications., K. van Dyke, C. van Dyke, and K. Woodfork, Editors. 2002, CRC Press: Boca Raton (FL). p. 539-555.

63. Funahashi, A., et al., CellDesigner: a process diagram editor for gene-regulatory and biochemical networks. Biosilico, 2003. 1(5): p. 159-162. 
A

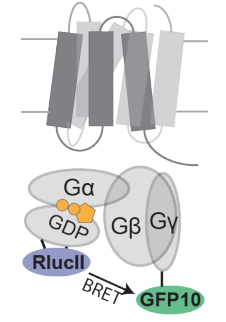

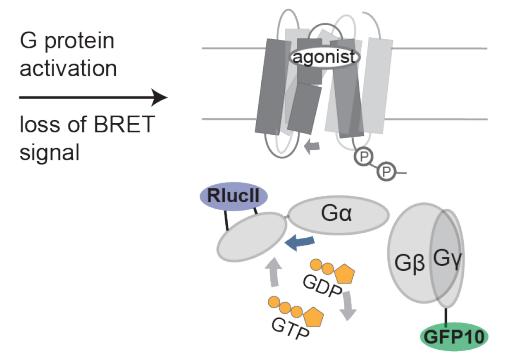

C
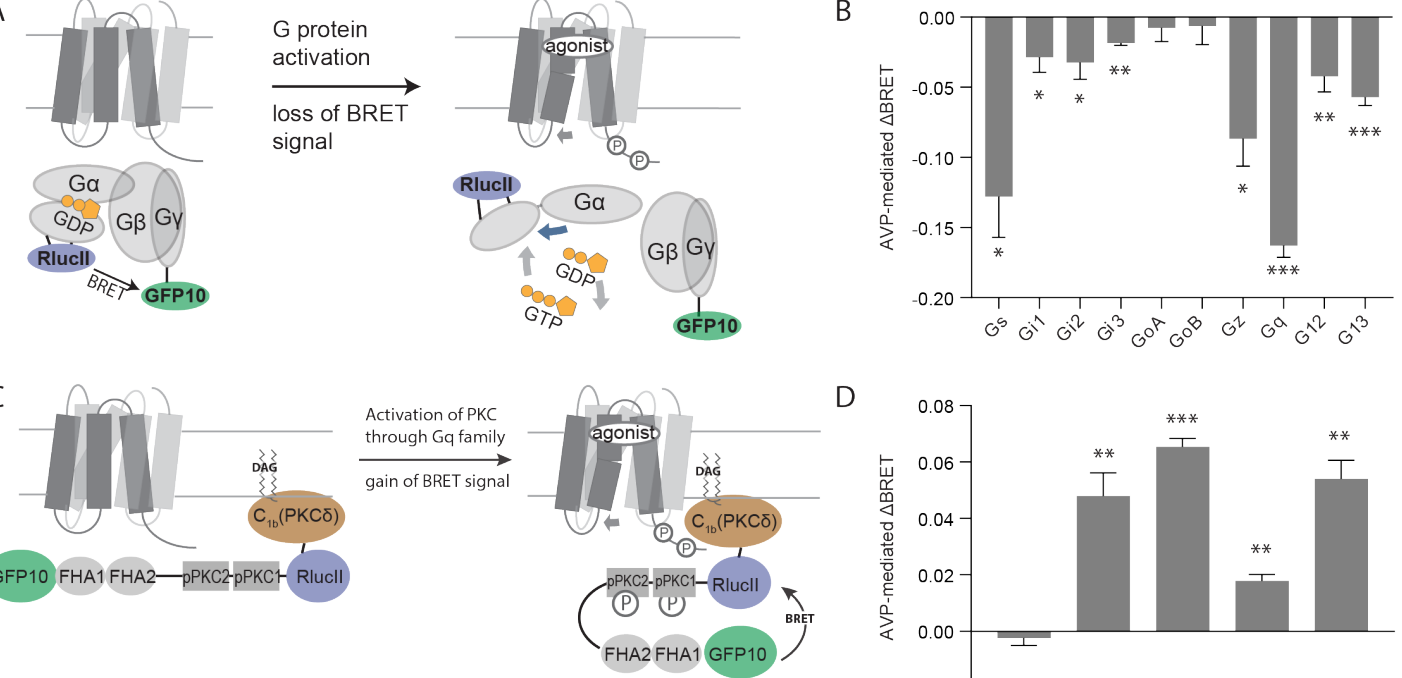

D
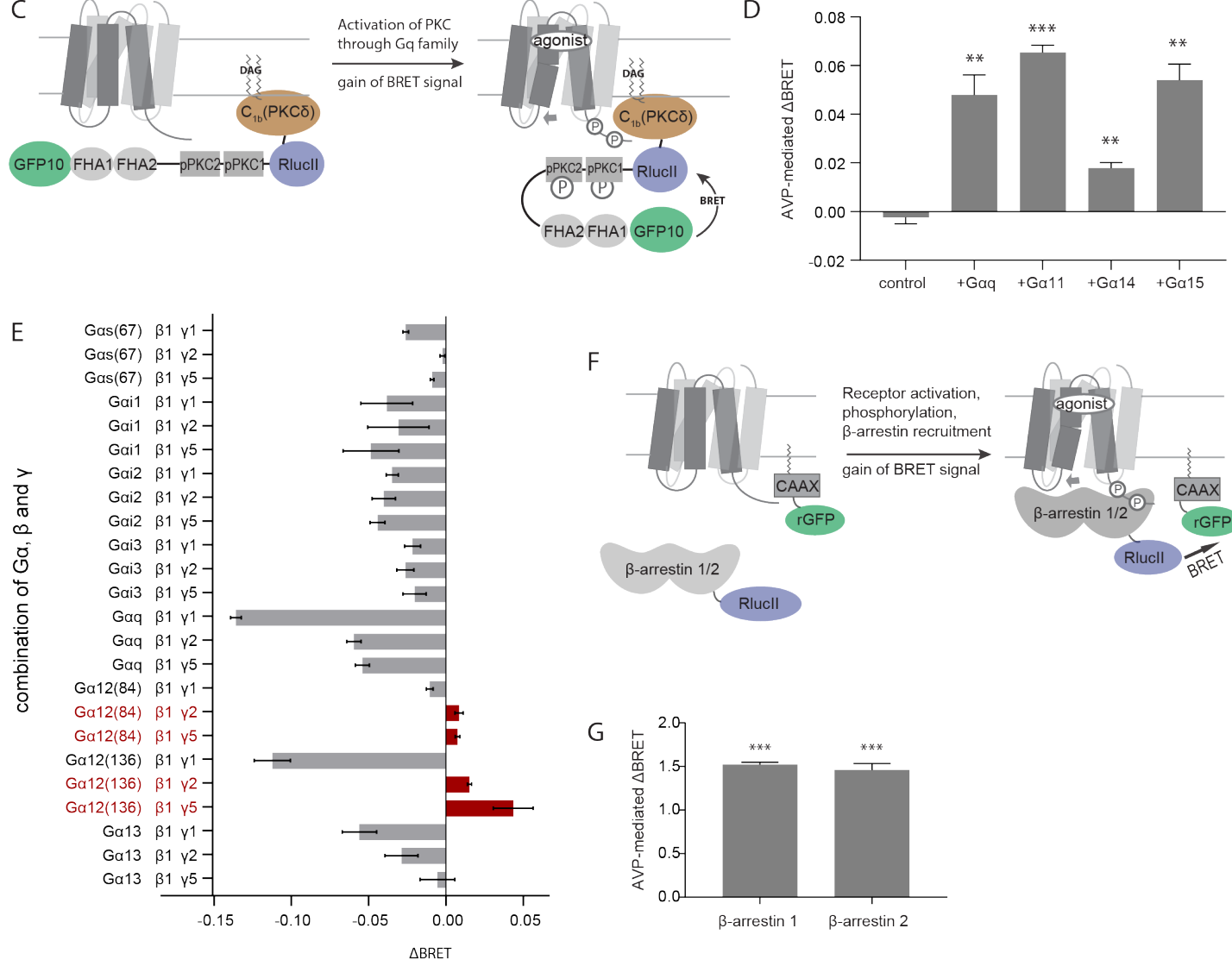

$\mathrm{F}$

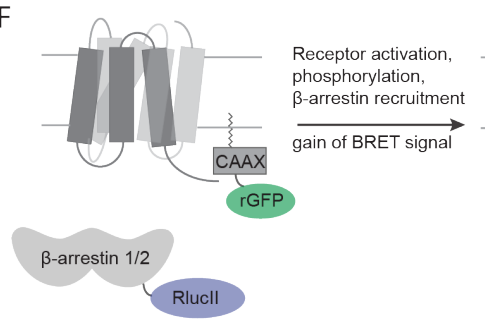

G

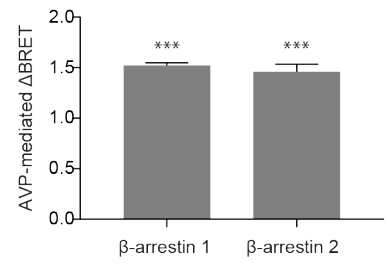

Figure 1. Vasopressin V2 receptor activates Gs/olf, Gi/o, $\mathrm{Gq} / 11$ and $\mathrm{G}_{12 / 13}$ family proteins and both $\beta$ arrestins. A. Schematic overview of the direct G protein BRET-based biosensor. Activation of the heterotrimeric $\mathrm{G}$ protein by the GPCR leads to dissociation of the $\mathrm{G} \alpha$ from G $\beta \gamma$ and a conformational change in the $G \alpha$ domain, which result in a decreased BRET signal. B. Overview of the argininevasopressin (AVP)-induced change in BRET signal for RlucII-tagged $\mathrm{G} \alpha$ subunits and GFP10-tagged G $\gamma 1$. C. Schematic overview of the protein kinase C (PKC) biosensor. GFP10 is followed by two phospho-sensing domains, FHA1 and FHA2 and two phospho-PKC (pPKC) sequences which can be phosphorylated by natively-expressed PKC, the RlucII and the $\mathrm{C} 1 \mathrm{~b}$ domain from $\mathrm{PKC} \delta$ which binds DAG, leading to membrane recruitment. Activation of the GPCR leads to activation of phospholipase $\mathrm{C} \beta$, followed by accumulation of diacylglycerol (DAG) which activates PKC. The PKC natively expressed in HEK293 cells phosphorylates pPKC1 and 2 domains of the PKC biosensor which causes a conformational change and BRET increase. Through the $\mathrm{C} 1 \mathrm{~b}$ domain of $\mathrm{PKC} \delta$, the sensor is recruited to DAG in the plasma membrane. D. Overview of the AVP-induced change in BRET signal for the $\mathrm{PKC}$ biosensor when different isoforms from the Gq/11 family are cotransfected in Gq/11/12/13 null HEK293 cells. E. G protein engagement at saturating AVP concentrations varies with $\mathrm{G} \gamma$ subunit. Different combinations of $\mathrm{G} \alpha$ and $\mathrm{G} \gamma$ lead to differing $\triangle \mathrm{BRET}$ values, numbers in brackets indicate the 
bioRxiv preprint doi: https://doi.org/10.1101/2021.01 28.427950; this version posted January 28, 2021. The copyright holder for this preprint (which was not certified by peer review) is the author/funder, who has granted bioRxiv a license to display the preprint in perpetuity. It is made available under aCC-BY 4.0 International license.

amino acid where RlucII was fused to $\mathrm{G} \alpha$. For $\mathrm{G} \alpha$ s, the alternative fusion position after amino acid 67 was used here. F. Schematic overview of the $\beta$-arrestin recruitment biosensor. Activation of the GPCR leads to phosphorylation of the $\mathrm{C}$-terminus of the receptor followed by recruitment of $\beta$-arrestin. $\mathbf{G}$. Overview of the AVP-induced change in BRET signal for RlucII-tagged $\beta$-arrestins and rGFP-tagged CAAX domain of Kras. The statistical significance was assessed by a one-sample t-test compared to 0 with $\mathrm{n}=3(* \mathrm{p}<0.05, * * \mathrm{p}<0.01$ and $* * * \mathrm{p}<0.001)$. Error bars are shown as standard error of mean (SEM).
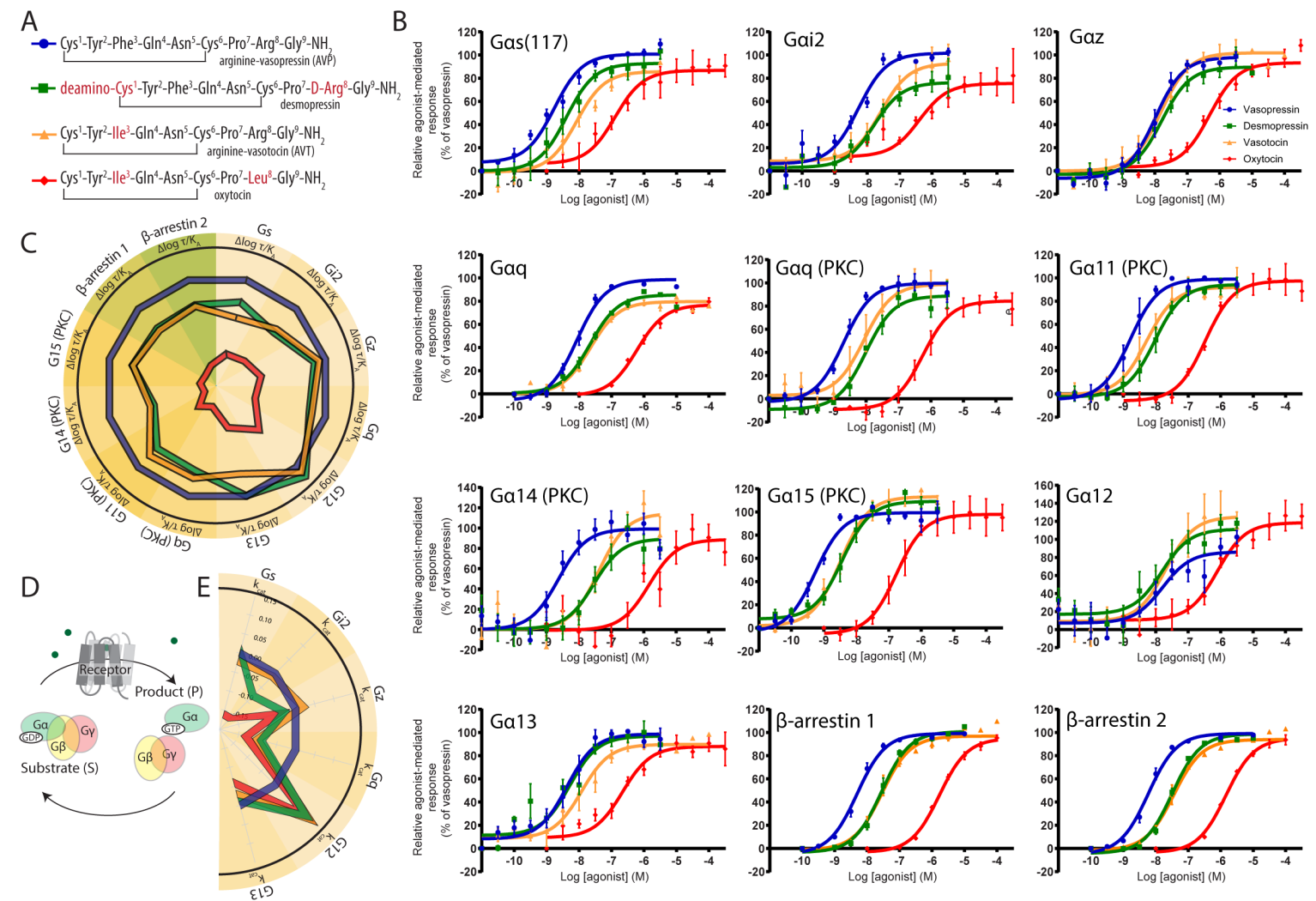

Figure 2. Biased signalling of V2R peptide ligands. A. The peptide ligands differ in only one or two amino acids (marked in red). B. Concentration-response curves of biosensor activation for all four peptides. C. Bias as calculated using the operational model for arginine vasopressin (AVP, blue), desmopressin (green), arginine vasotocin (yellow) and oxytocin (red). D. The schematic diagram of the Michaelis-Menten model of $\mathrm{G}$ protein activation. E. The Michaelis-Menten signalling bias. 
A

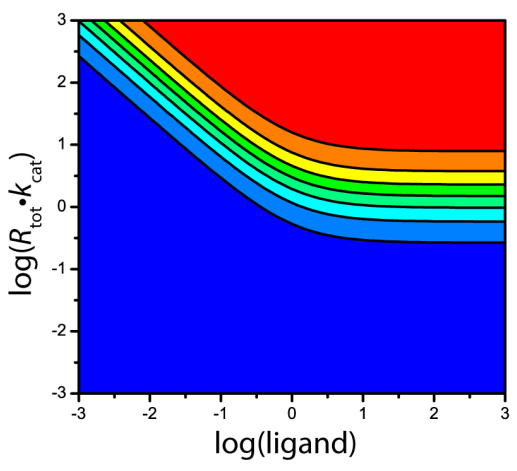

C

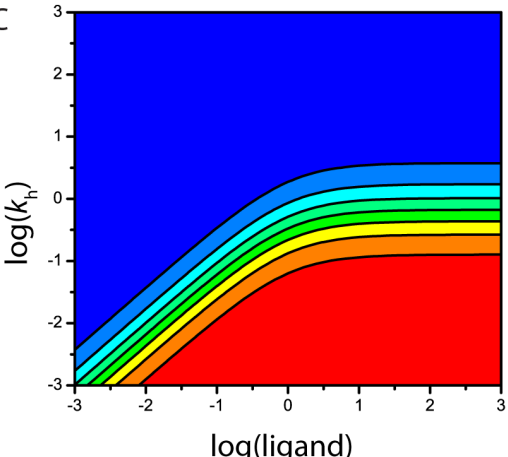

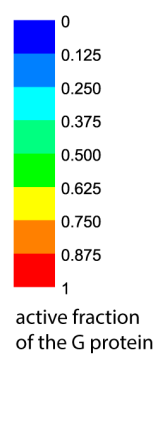

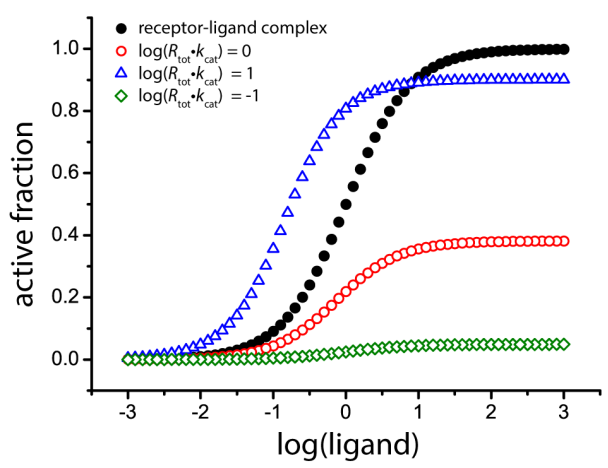

D

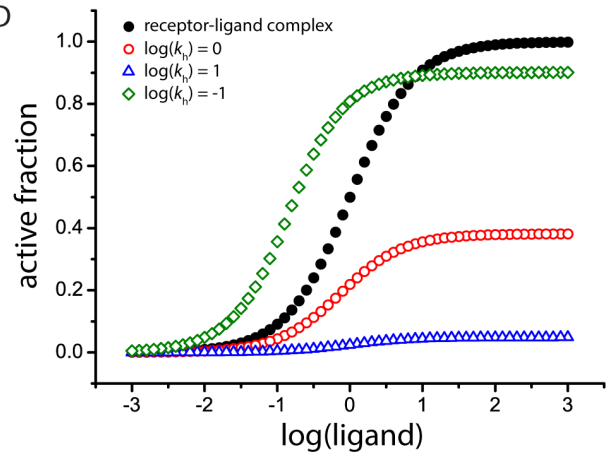

Figure 3. Activation of the $\mathrm{G}$ protein modelled according to the Michaelis-Menten formalism so that $\mathrm{G}$ protein activation is half maximal and $\log ($ ligand $)=0$ refers to the ligand concentration where the concentration of ligand equals $K_{\mathrm{d}} . R_{t o t} \cdot k_{c a t}$ was modelled as one parameter because a high receptor number $\left(R_{t o t}\right)$ can compensate for a slow $k_{c a t}$ and vice versa. The units are arbitrary. (A) Fraction of active $\mathrm{G}$ protein as a function of receptor activity and amount $\left(R_{t o t} \cdot k_{c a t}\right)$. (B) examples of individual curves of (A) at several receptor activity levels. (C) Fraction of active $G$ protein as a function of $G$ protein deactivation rate constant $k_{\mathrm{h}}$. (D) examples of individual curves at different $\log \left(k_{\mathrm{h}}\right)$ values. Both parameters can result in a shift of the EC50 value as well as the amplitude of the response. 

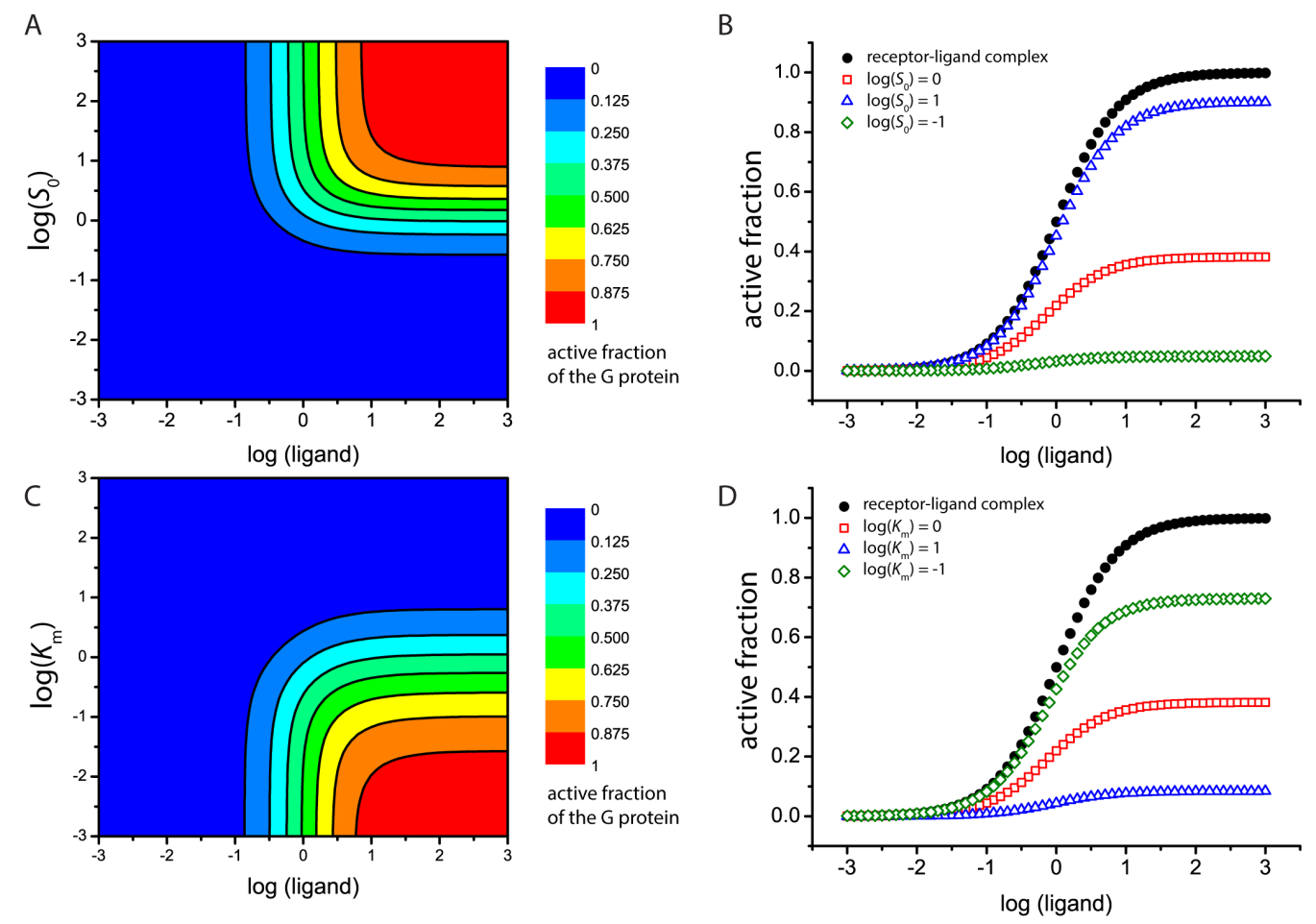

Figure 4. Dependence of G protein activation on total G protein concentration $S_{0}$ and the Michaelis constant $K_{\mathrm{m}}$ for G protein-receptor interaction. Either $S_{0}$ or $K_{\mathrm{m}}$ was varied, the other parameters were kept constant. In addition, the ligand concentration was varied over three orders of magnitude. (A) The fraction of active $\mathrm{G}$ protein is shown as a function of the total amount of $\mathrm{G}$ protein in the system $\left(S_{0}\right)$, assuming a $K_{\mathrm{m}}$ value of $1\left(S_{0}=K_{\mathrm{m}}\right.$ at $\left.\log \left(S_{0}\right)=0\right)$. (B) examples of individual curves at several $\mathrm{G}$ protein concentrations. (C) The fraction of active $\mathrm{G}$ protein as a function of the $K_{\mathrm{m}}$ value between the receptor and the $G$ protein. The lower the value, the stronger the interaction. (D) Examples of the concentration-response curves normalised to the total amount of the G protein in the system.

The EC50 value is not affected by these parameters, but the amplitude is. 


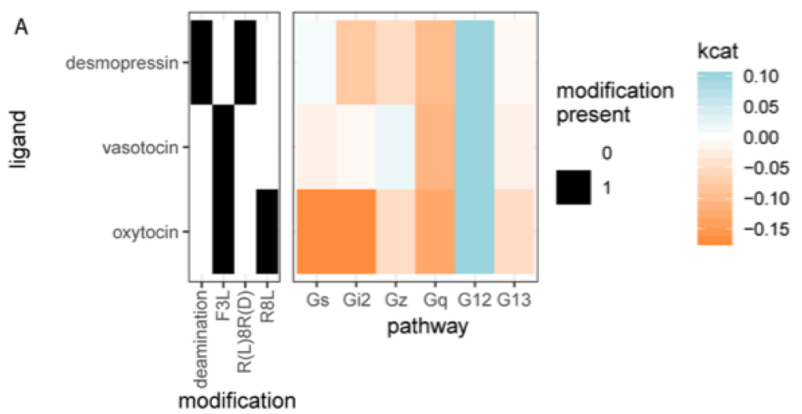

B

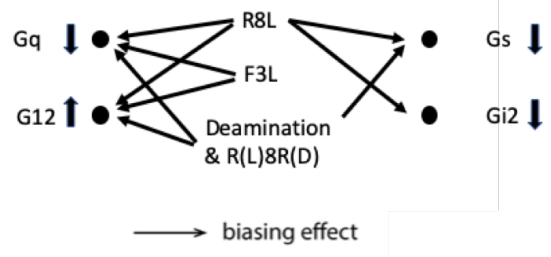

Figure S1. Correlation of the peptide modifications relative to the AVP with their signalling properties. A. A heat map showing the $k_{\text {cat }}$ values. B. Observed trends of peptide modification on biased signalling. 